\title{
Detecting the Prevalence of Chagas Disease among People Living with HIV/AIDS in Los Angeles County, California
}

Tyler Evans ${ }^{1 *}$, Selena P Than ${ }^{2}$, Leonardo Colemon ${ }^{1}$, Adam Carl Sukhija-Cohen ${ }^{1}$ and Otto O Yang ${ }^{2}$

${ }^{1}$ Department of Medicine, AIDS Healthcare Foundation, Los Angeles, CA, US

${ }^{2}$ California State University Northridge, Northridge, CA, US

*Corresponding author: Tyler Evans, Department of Medicine, AIDS Healthcare Foundation, Los Angeles, CA, 90027, United States, Tel: 9176481068 ; E-mail: tyler.evans@aidshealth.org

Received date: July 25, 2018; Accepted date: September 21, 2018; Published date: September 30, 2018

Copyright: (c) 2018 Evans T, et al. This is an open-access article distributed under the terms of the Creative Commons Attribution License; which permits unrestricted use; distribution; and reproduction in any medium; provided the original author and source are credited.

\begin{abstract}
Background: Chagas disease (CD) is a well-known tropical parasitic disease with a historical footprint in Latin America. Special populations, including people living with HIVIAIDS (PLWHA), may be at a higher risk of CD and its progression to adverse outcomes. The objective of this study is to measure the prevalence of $C D$ among Latin American foreign-born PLWHA residing in Los Angeles (LA) County (LAC), CA.
\end{abstract}

Methods: Retrospective data analysis of Latin American foreign-born PLWHA aged 18 years and older seeking primary care services at AIDS Healthcare Foundation (AHF) Healthcare Centers between 05/01/2017 and 03/31/2018. Descriptive analyses were performed using frequency distributions and nonparametric Chi-square tests to examine the prevalence of $C D$.

Results: Two clients out of a sub-population of 179 were identified as CD-positive $(p<0.01)$ : one male and one female, both originating from Honduras. The prevalence documented at AHF Healthcare Centers $(1.11 \%)$ is slightly lower than the $1.24 \%$ prevalence reported previously in LAC $(1.24 \%)$.

Conclusion: While this is a relatively small sample size, the statistically significant results suggest developing $C D$ testing and treatment guidelines among Latin American foreign-born PLHWA-a prominent subpopulation in LAC.

Keywords: Chagas disease; Travel; Infectious disease; Tropical disease; People living with HIV/AIDS

\section{Introduction}

Chagas disease (CD) is a well-known and complex zoonosis caused by the protozoan parasite Trypanosoma cruzi with a historical footprint in 21 Latin American countries [1]. While the infection is often asymptomatic, it has the potential to cause significant chronic disease-particularly affecting the gastrointestinal and cardiovascular systems [2,3]. While the burden of disease is well documented in nations of classically high prevalence, its detection in the global north has not been well characterized until recently [4] having said that, a systematic system of detection is certainly lacking-especially among special populations [3]. According to the Centers for Disease Control and Prevention (CDC), there are 300,000 cases estimated in the US alone [2]. What was not clear until recently was a description of the burden of disease among American migrants from nations without well-established prevalence ratios. However, Meymandi et al. published a recent analysis of foreign-born Latin Americans currently living in Los Angeles (LA) county (LAC), CA, and reported a $1.24 \%$ general prevalence [5].

In addition to a general dearth of surveillance in the global north, what is not well known is which populations may be at higher risk for CD. People living with HIV/AIDS (PLWHA) represent a high-risk population for disease transmission as well as a number of adverse outcomes. Consequently, it has been theorized that a pre-existing HIV infection may lead to a greater risk of CD infection as well as a likely progression to more adverse events [6]. To that point, Almeda et al performed a literature review of co-morbidity cases of HIV/AIDS and CD between 1980 and 2010, and documented a wide range of prevalence ratios from more than $75 \%$ in Brazil $(\mathrm{n}=222)$, followed by Argentina (19.2\%) $(n=56)$, the US $(1.7 \%)(n=5)$, Chile $(1.7 \%)(n=5)$, and Spain $(1.0 \%)(n=3)$ [7]. In addition to higher suspected rates of $\mathrm{CD}$ transmission. published on higher rates of parasitemia among PLWHA [8]. Moreover, PLWHA with lower CD4 T-cell counts are at higher risk of $\mathrm{CD}$ reactivation, which results in an increased risk of fatality $[6,9,10]$.

While this heightened risk of $\mathrm{CD}$ among PLWHA has been documented, what is not clear is prevalence of CD/HIV co-infectivity in the US. Consequently, this study aims to explore the prevalence of CD among Latin American foreign-born PLWHA residing in LAC who sought clinic services at the AIDS Healthcare Foundation (AHF), the largest nonprofit provider of primary care services for PLWHA in the US [11].

\section{Materials and Methods}

\section{Study design and population}

We conducted a retrospective analysis of 179 patients $\mathrm{HIV}^{+}$patients who sought primary care services at AHF Healthcare Centers between May 1, 2017 and April 30, 2018. AHF serves over 50,000 patients in the US with over $7000\left(\right.$ mostly $\left.\mathrm{HIV}^{+}\right)$in the US. They provide HIV 
Page 2 of 3

specialist services in addition to general primary care. Clients were included in the analysis if they were 1 . Between the ages of 18 years and 15 years; 2. Born in any country in Latin America, 3. Diagnosed with HIV; 4. Sought primary care service at AHF in LAC; and 5. Received a test for CD during the study period. Clients were excluded if they did not receive a test for CD and were over age 50.

\section{Independent variables}

Data collection using AHF's electronic medical record system (Centricity Practice Solution, GE Healthcare) explored the following predictor variables: age, gender, country of origin, and year of immigration.

\section{Dependent variables}

The outcome variable of interest was $\mathrm{CD}$ status, which was determined by qualitative assay using the FDA-approved Abbott Prism Chagas assay (Abbott Laboratories, Lake Bluff, IL). Any preliminary positive result was sent to the LAC department of public health laboratory, which was further sent to the CDC to perform a confirmatory testing. Confirmatory testing was provided by combined ELISA/western blot sequencing.

\section{Data analysis}

A descriptive analysis was performed using frequency distributions and non-parametric Chi-square tests to examine the prevalence of $\mathrm{CD}$ by age, gender and country of origin. Frequency distributions were used to describe the participants' demographics and $\mathrm{CD}$ status. Categorical predictor variables were compared between CD-positive and CD-negative groups using Fisher's exact test. Statistical analyses were conducted using SPSS Statistics 23 (IBM Corporation, Armonk, NY).

\section{Results}

Out of the 179 clients in the study, 150 (83.8\%) self-identified as male, 13 self-identified as female, and 16 self-identified as transgender (either male-to-female or female-to-male). More than half $(\mathrm{n}=103$; $57.5 \%$ ) of the study population migrated from Mexico, followed by 26 (14.5\%) from El Salvador, 18 (10.1\%) from Guatemala, 15 (8.4\%) from Colombia, and seven (3.9\%) from Honduras. The majority of the study population $(n=118 ; 65.9 \%)$ identified Spanish as their primary language. The mean age based on the clients' dates of birth was 47 years old (SD: 11 years). 68 participants (38.0\%) reported the year of their migration, and the mean age at migration was 25 years (SD: 9 years). Table 1 shows the demographic characteristics of the study population.

\begin{tabular}{|l|l|l|}
\hline Variable & $\mathbf{n}(\mathbf{S D})$ & $\%$ \\
\hline Mean Age in Years & $47(11)$ & \\
\hline Mean Age in Years at First Migration ${ }^{*}$ & $25(9)$ & \\
\hline Gender & & \\
\hline Female & 13 & 7.3 \\
\hline Male & 150 & 83.8 \\
\hline Transgender & 16 & 8.9 \\
\hline
\end{tabular}

\begin{tabular}{|c|c|c|}
\hline \multicolumn{2}{|c|}{ Country of Origin } & \multirow[b]{2}{*}{57.5} \\
\hline Mexico & 103 & \\
\hline El Salvador & 26 & 14.5 \\
\hline Guatemala & 18 & 10.1 \\
\hline Colombia & 15 & 8.4 \\
\hline Honduras & 7 & 3.9 \\
\hline Other & 10 & 5.6 \\
\hline \multicolumn{2}{|c|}{ Primary Language } & \\
\hline Spanish & 118 & 65.9 \\
\hline English & 61 & 34.1 \\
\hline \multicolumn{3}{|c|}{ SD: Standard Deviation. } \\
\hline
\end{tabular}

Table 1: Demographic characteristics of the study population $(\mathrm{N}=179)$.

While we had 5 preliminary positive results (based on the Abbot prism assay), the CDC test (describe here again) only confirmed 2 of these cases, with an overall prevalence of $1.11 \%$. There were clinical findings, found in both patients (found on EKG). This was slightly lower than Meymandi et al. [5] findings described above (1.24\%) [3] Of the 2 cases, there was one cis male and female. Both of the CDpositive cases migrated from Honduras, with a specific prevalence of $28.6 \%(p=0.257)$. Our findings found no statistically significant association between age, gender, and CD status. However, we did find a statistically significant association between country of origin and CD status. Table 2 illustrates this data further.

\begin{tabular}{|l|l|l|l|l|}
\hline Variable & $\begin{array}{l}\text { CD+ } \\
\text { Cases } \\
(\%)\end{array}$ & $\begin{array}{l}\text { CD- } \\
\text { Cases } \\
(\%)\end{array}$ & $\begin{array}{l}\text { CD Prevalence (95\% } \\
\text { CI) }\end{array}$ & p-value \\
\hline Total & $2(1.1)$ & $177(98.9)$ & $1.1 \%(-0.004,0.026)$ & $<0.001$ \\
\hline Age Group in Years & $0(0.0)$ & $26(14.7)$ & - & $1^{*}$ \\
\hline $24-34$ & $1(50.0)$ & $47(26.6)$ & $2.1 \%(-0.020,0.062)$ & $<0.001$ \\
\hline $35-44$ & $1(50.0)$ & $68(38.4)$ & $1.4 \%(-0.014,0.042)$ & $<0.001$ \\
\hline $45-54$ & $0(0.0)$ & $36(20.3)$ & - & - \\
\hline $55+$ & $1(50.0)$ & $12(6.8)$ & $7.7 \%(-0.068,0.222)$ & 0.002 \\
\hline Gender & $1(50.0)$ & $149(84.2)$ & $0.7 \%(-0.006,0.020)$ & $<0.001$ \\
\hline Female & $0(0.0)$ & $16(9.0)$ & - & $0.148^{*}$ \\
\hline Male & $0(0.0)$ & $103(58.2)$ & - & - \\
\hline Transgender & $0(0.0)$ & $26(14.7)$ & - & - \\
\hline Country of Origin & $0(0.0)$ & $18(10.2)$ & - & - \\
\hline Mexico & $15(8.5)$ & - & - \\
\hline El Salvador & & & & - \\
\hline Guatemala & & & & - \\
\hline Colombia & $0.01 *$ & - \\
\hline
\end{tabular}


Citation: Evans T, Than SP, Colemon L, Sukhija-Cohen AC, YanG OO (2018) Detecting the Prevalence of Chagas Disease among People Living with HIVIAIDS in Los Angeles County, California. J Trop Dis 6: 282. doi:10.4172/2329-891X.1000282

Page 3 of 3

\begin{tabular}{|l|l|l|l|l|}
\hline Honduras & $2(100.0)$ & $5(2.8)$ & $28.6 \%(-0.049,0.621)$ & 0.257 \\
\hline Other & $0(0.0)$ & $10(5.6)$ & - & - \\
\hline
\end{tabular}

CD: Chagas Disease; $\mathrm{Cl}$ : Confidence Interval.

*Fisher's Exact Test.

Table 2: Prevalence of Chagas disease by age, gender, and country of origin.

\section{Discussion}

CD was first discovered in LAC in 1984. While CD prevalence in LAC has been documented, this study is one of only a few that investigated CD comorbidity among PLWHA, and the first to describe it among US migrants. These findings provide a better understanding of the current prevalence of $\mathrm{CD}$ among PLWHA residing in a bordering area to Latin America.

While the CD prevalence was lower than expected, and CD does not appear to be higher among PLWHA, a prevalence of $>1 \%$ provides further evidence to advocate for better surveillance systems to detect this deleterious disease. What was also of interest was that both reported cases were from Honduras, with no other cases reported in Latin America. This was not consistent with the data reported by Meymandi et al. [5]. While we do not demonstrate a need for a heightened surveillance system for PLWHA, we believe we have provided evidence for more systematic surveillance systems in migrants living in the US.

\section{Limitations}

There are several limitations that should be considered when interpreting our findings. First, this retrospective study utilized secondary data that were not initially intended to study prevalence of $\mathrm{CD}$. As a result, there were a limited number of predictor variables to include in the analysis as well as possible confounders that could not be measured or controlled. Second, clients who sought primary care service at AHF Healthcare Centers may experience recall bias when answering providers' questions. Third, the sample size of our population was too small to measure risk of $\mathrm{CD}$ co-infection among PLWHA.

\section{References}

1. WHO (2017) Chagas disease (american trypanosomiasis)

2. CDC (2017) Chagas disease 2017.

3. Rassi AJ, Rassi A, Marin-Neto JA (2010) Chagas disease. Lancet 375: 1388-1402.

4. Cambronero-Cortinas E (2016) Epidemiology of Chagas disease in nonendemic european countries. Int Cardiovasc Forum J 7: 11-14.

5. Meymandi SK, Forsyth CJ, Soverow J, Hernandez S, Sanchez D, et al. (2017) Prevalence of Chagas disease in the latin american-born population of los angeles. Clin Infect Dis 64: 1182-1188.

6. Sartori AMC, Ibrahim KY, Nunes Westphalen EV, Braz LMA, Oliveira Jr OC, et al. (2007) Manifestations of Chagas disease (American trypanosomiasis) in patiennts with HIV/AIDS. Ann Trop Med Parasitol 101: 31-50.

7. de Almeida EA, Ramos Junior AN, Correia D, Shikanai-Yasuda MA (2011) Co-infection Trypanosoma cruzi/HIV: systematic review (1980-2010). J Brazilian Soci Trop Med 44: 762.

8. de Freitas VL, da Silva SC, Sartori AM, Bezerra RC, Westphalen EV, et al. (2011) Real-time PCR in HIV/Trypanosoma cruzi coinfection with and without Chagas disease reactivation: association with HIV viral load and CD4 level. PLoS Negl Trop Dis 5: e1277.

9. Bennchetrit AG, Fernandez M, Bava AJ, Corti M, Porteiro N, et al. (2018) Clinical and epidemiological features of chronic Trypanosoma cruzi infection in patients with HIV/AIDS in Beunos Aries, Argentinna. Int J Infecti Dis 67: 118-121.

10. Martins-Melo FR, Ramos Jr AN, Alencar CH, Heukelbach J (2012) Mortality related to chagas disease and HIV/AIDS coinfection in Brazil. J Trop Med 1-4.

11. Stauffert D, Silveira MF, Mesenburg MA, Manta AB, Dutra AD, et al. (2017) Prevalence of Trypanosoma cruzi/HIV coinfection in southern Brazil. Braz J Infect Dis 21: 180-184. 